\title{
As dimensões humana, instrumental e estratégica da Comunicação Organizacional: recorte de um estudo aplicado no segmento corporativo*
}

\author{
Margarida M. Krohling Kunsch**
}

\section{Resumo}

Na perspectiva de que a Comunicação que ocorre no dia a dia nas organizações assume, entre outras, três principais dimensões (humana, instrumental e estratégica), o principal objetivo desta pesquisa empírica foi verificar, junto a uma amostra representativa de empresas atuantes no território brasileiro, como essas dimensões estão presentes nas práticas cotidianas de Comunicação. Aplicou-se questionário junto a 36 empresas a partir de uma a mostra de 258. Os dados obtidos mostram que a Comunicação vem sendo praticada nessas três dimensões. As organizações evoluíram gradativamente dos modelos mecânicos da transmissão unilateral de informações para a implantação de processos comunicativos mais interativos. No entanto, ainda falta uma Comunicação que permita a abertura de canais dialógicos de fato e que possibilite maior valorização das pessoas.

Palavras chave: Comunicação. Organizações. Dimensões. Humanização. Pesquisa

* Este estudo integra o projeto "As dimensões humana, instrumental e estratégica da Comunicação Organizacional: um estudo teórico e aplicado", vinculado à ECA-USP e ao $\mathrm{CNPq}$ - Conselho Nacional de Desenvolvimento Científico e Tecnológico e contou com a participação dos bolsistas de Iniciação Científica: Álvaro Marinho Marques e Nathália Pereira Guerra Simões e a colaboração de Anna Paula Muniz Costa de Andrade. Originalmente este artigo foi apresentado no VI Congresso Abrapcorp 2012. ** Professora doutora titular do Programa de Pós-Graduação em Comunicação Social, Escola de Comunicações e Artes da Universidade -ECA, Universidade de São Paulo. Autora e organizadora coletâneas de Comunicação, Comunicação Organizacional e Relações Públicas. Foi presidente, em duas gestões, da Sociedade Brasileira de Estudos Interdisciplinares da Comunicação (Intercom), da Asociación Latinoamericana de Investigadores de la Comunicación (Alaic) e da Associação Brasileira de Pesquisadores de Comunicação Organizacional e de Relações Públicas (Abrapcorp). Ex-presidente da Confederação Ibero-Americana das Associações Científicas e Acadêmicas de Comunicação (Confibercom). É presidente da Federação Brasileira das Associações Científicas e Acadêmicas de Comunicação (Socicom) e vice presidente da AssIbercom associação Iberoa-Americana da Comunicação. São Paulo-SP, Brasil. E-mail: mkkunsch@usp.br.

Intercom - RBCC

São Paulo, v.35, n.2, p. 267-289, jul./dez. 2012

267 
The human, the instrumental and the strategic dimensions of organizational communication: empirical study in corporations Abstract

Communication that occurs routinely in organizations can happen in three main dimensions: human, instrumental and strategic. The main goal of this paper was to verify how these dimensions are present in communicational daily practices in a representative sample of Brazilian corporations. We applied a questionnaire to 36 companies from a sample of the 258 . The data collected showed that communication happens in the three mentioned dimensions. Organizations have slowly evolved from mechanical practices of unilateral communication to more interactive processes. However, they still need practices of communication that allow for truly dialogical relationships and that focus on people's worth.

Keywords: Communication. Organizations. Dimensions. Humanization. Research.

\section{Las dimensiones humana, instrumental y estratégica de la comunicación organizacional: recorte de un estudio aplicado en el segmento corporativo}

\section{Resumen}

Bajo la perspectiva de que la comunicación en/de las organizaciones asume, entre otras, tres dimensiones esenciales (humana, instrumental y estratégica), el principal objetivo de esta investigación empírica ha sido verificar, en una muestra representativa de empresas que actúan en el territorio brasileño, si y como tales dimensiones están presentes en las prácticas cotidianas de comunicación. Se aplicó un cuestionario a 36 empresas a partir de una muestra de 258. Los datos obtenidos revelan que la comunicación es practicada en esas tres dimensiones. Las organizaciones han evoluido progresivamente de los modelos mecánicos de la transmisión unilateral de informaciones hacia la implantación de procesos comunicativos más interactivos. Todavía aun hace falta una comunicación que permita abrir canales dialógicos realmente efectivos y que posibilite una valorización mayor de las personas.

Palabras clave: Comunicación. Oorganizaciones. Dimensiones. Humanización. Investigación.

\section{Introdução}

\footnotetext{
demanda crescente da sociedade por uma Comunicação 4 transparente, comportamento ético e ações que visem 1 atender às necessidades da comunidade no entorno, tendo em vista a manutenção de uma boa imagem perante a opinião pública, culminam na necessidade de uma Comunicação profissionalizada e competente por parte das empresas.
} 
AS DIMENSÕES HUMANA, INSTRUMENTAL E ESTRATÉGICA DA COMUNICAÇÃO...

A Comunicação e a humanização nos contextos organizacionais constituem um grande desafio para os executivos e gestores. As organizações evoluíram gradativamente dos modelos mecânicos da transmissão unilateral de informações para a implantação de processos comunicativos mais interativos e simétricos. No entanto, acreditamos que ainda falta uma Comunicação que permita a abertura de canais dialógicos de fato e que possibilite maior valorização das pessoas.

Há todo um caminho a percorrer frente às incertezas da sociedade contemporânea e o mercado altamente competitivo que provocam angústias, ansiedades e pressões sobre as pessoas no ambiente organizacional. Como a Comunicação poderá contribuir para amenizar esta realidade?

Os gestores de Comunicação estão conscientes da dimensão humana da Comunicação Organizacional ou estão mais preocupados com a instrumentalidade e visão estratégica de resultados dessa Comunicação? São questões que nos têm motivado a estudar e refletir.

principal objetivo desta pesquisa empírica foi verificar, junto a uma amostra representativa de organizações atuantes no território brasileiro, como as dimensões humana, instrumental e estratégica estão presentes nas práticas cotidianas de Comunicação e quais são predominantes, a fim de manter o relacionamento com seus públicos estratégicos. A pesquisa foi realizada com base na aplicação de questionário junto a amostra de 36 empresas, conforme será explicitado mais adiante. Entendendo que a Comunicação que ocorre no dia a dia das organizações assume entre outras três principais dimensões (humana, instrumental e estratégica), o objetivo principal foi verificar como essas mesmas dimensões são contempladas nas empresas estudadas.

\section{Dimensões da Comunicação Organizacional: reflexões e aportes teóricos}

Além de todos os conceitos já trabalhados e explorados por inúmeros autores sobre o significado e a abrangência da Comunicação Organizacional, temos tentado buscar novos olhares para 
compreender como essa Comunicação está configurada hoje e quais são suas dinâmicas nas práticas organizacionais. Para tanto, propomos analisá-la em três dimensões: humana, instrumental e estratégica. Em estudos anteriores (Kunsch, 2006, 2009 e 2010) ${ }^{1}$ esta temática já foi desenvolvida, tendo-se procurado também fundamentá-la teoricamente.

A principal fonte de inspiração da presente análise vem de uma reflexão sobre o livro Pensar a Comunicação, de Dominique Wolton (2004), quando o autor analisa a dimensão normativa e humanista da Comunicação, comparando-a com a visão instrumental dominada pela técnica e por interesses econômicos. Em síntese, Wolton enaltece o poder que a Comunicação e a mídia exercem na sociedade contemporânea como uma realidade incontestável, quando afirma: "A Comunicação é um dos mais brilhantes símbolos do século XX; seu ideal de aproximar os homens, os valores e as culturas compensa os horrores e as barbaridades de nossa época" (WOLTON, 2004, p.27). Por outro lado, chama a atenção para as discrepâncias e os problemas decorrentes do triunfo técnico e econômico dessa mesma Comunicação em relação à sociedade. Assim, o autor questiona:

Como salvar a dimensão soberba da Comunicação, uma das mais belas do homem, aquela que o faz desejar entrar em relação com os outros, interagir com os outros, quando tudo está ao contrário, voltado para o sentido dos interesses? Como salvar a dimensão humanista da Comunicação, quando

triunfa sua dimensão instrumental? Que relação existe entre o ideal da Comunicação, que atravessa os tempos e as civilizações transformando-a em um dos símbolos mais fortes da humanidade, e os interesses e ideologias do mesmo nome (WOLTON, 2004, p.28)? (Grifos nossos).

Se direcionarmos essas reflexões para a Comunicação Organizacional, veremos que essa ambiguidade também está presente na Comunicação nas e das organizações. Há todo um discurso institucional enaltecendo o valor e os ideais da Comunicação

\footnotetext{
${ }^{1}$ Para maiores detlahes sobre a questão da Comunicação e humanização das organizações sugere-se consultar: KUNSCH, Margarida M. Krohling (Org.). A Comunicação como fator de humanização das organizações. São Caetano do Sul, SP: Difusão Editora, 2010.
} 
humana. No entanto, nota-se no cotidiano das organizações em geral, ainda que nas entrelinhas, uma predominância da Comunicação técnica e da busca da eficácia das mensagens e ações comunicativas. Afirma Wolton (2004, p.37) "que é possível racionalizar a Comunicação humana como se pode racionalizar a Comunicação técnica. Mas se a racionalidade das técnicas de Comunicação é muito superior à racionalidade da Comunicação humana, ela é ao mesmo tempo muito mais pobre".

Com base nesse autor, o grande risco quanto a essas duas formas de Comunicação é querer limitar esse abismo insuperável entre as duas e procurar "racionalizar a Comunicação intersubjetiva para torná-la mais eficaz. Ou, em outras palavras, acreditar que a Comunicação funcional, desmultiplicada pelas técnicas, a aproximaria da Comunicação normativa" (WOLTON, 2004, p.39).

A seguir procuraremos descrever e fundamentar alguns pontos que possam permitir caracterizar o significado de cada uma dessas três dimensões - instrumental, estratégica e humana - da Comunicação Organizacional.

A dimensão instrumental é a predominante nas organizações em geral. Caracteriza-se como funcional e técnica. É aquela que é considerada mais como transmissão de informações e como instrumento para viabilizar os processos e permitir o pleno funcionamento de uma organização para o alcance dos seus objetivos globais. Trata-se da visão linear da Comunicação e que ignora contextos e outros aspectos mais subjetivos. Evidentemente é necessária e sempre existirá.

A dimensão estratégica da Comunicação Organizacional se assemelha muito com a instrumental. Está relacionada com a visão pragmática da Comunicação, como as açõescomunicativas propriamente ditas e com vistas à eficácia e aos resultados. É considerada um fator que agrega valor à organização e aos negócios. Alinha-se, estrategicamente, por meio do planejamento e da gestão, aos objetivos globais da organização e aos princípios estabelecidos em relação a sua missão, sua visão e seus valores.

Não é possível desconsiderar a Comunicação humana e as múltiplas perspectivas que permeiam o ato comunicativo no interior das organizações. Daí a importãncia da dimensão humana. Em 
primeiro lugar, temos que pensar na Comunicação entre as pessoas e que os seres humanos não vivem sem se comunicar.

O ambiente organizacional é uma realidade social vivenciada por pessoas que nela convivem. Estas necessitam ser consideradas e valorizadas no fazer comunicativo diário, sem ser sufocadas pelo excesso de Comunicação técnica e instrumental, focada somente nos resultados e nos interesses dos negócios das empresas. Entende-se que iniciativas como a abertura de canais diretos de diálogo entre a alta direção e os trabalhadores possam ser um caminho para valorização das pessoas nas organizações. Nosso grande interesse, no momento, é exatamente aprofundar os estudos sobre como a Comunicação poderá contribuir para a humanização das organizações em um mundo complexo onde as pessoas sofrem pressões de todos os lados, não sendo diferente no âmbito das organizações.

Atentar para a humanização das organizações nunca foi tão necessário como no mundo globalizado e desigual de hoje, no qual o emprego é privilégio de poucos e esses poucos precisam, muitas vezes, trabalhar para muitos se quiserem continuar empregados. Essa dicotomia é muito problemática para a vida do indivíduo no trabalho. Conforme Odair Furtado (2003, p.321), existe,

para o trabalhador que mantém o emprego, o risco constante da demissão e para o desempregado, a pouca esperança de voltar ao mercado de trabalho. [São] fontes de tensão que [...] desorganizam a vida do trabalhador e de sua família. Neste momento, estamos tratando do desemprego como fator emergente central para o sofrimento psíquico do trabalhador, mas os que permanecem empregados também sofrem pressões que representam um fator forte de risco que vem sendo estudado pelos pesquisadores que usam a referência da psicopatologia do trabalho.

Essa realidade crucial muito presente nos dias de hoje põe em cheque tudo aquilo que se defende como humanização, qualidade de vida no trabalho e as apologias da valorização das pessoas, da gestão de talentos, de Comunicação interna participativa etc.

Selma Lancman (2009), professora da Faculdade de Medicina da Universidade de São Paulo, ao abordar as novas formas de trabalho na sociedade globalizada e da era digital bem como as implicações entre o mundo externo e o mundo interno do 
trabalhador, chama atenção para os inúmeros suicídios que vem ocorrendo em grandes empresas e cita o caso da France Télécom que registrava cerca de 24 nos últimos 18 meses em fins de 2009. Para esta pesquisadora "o alerta francês evidencia a necessidade de repensarmos o trabalho na atualidade e, sobretudo seu impacto na saúde mental das pessoas (p.69)."

Acreditamos que a questão da Comunicação humana nas organizações deva em futuro próximo vir a ocupar novos espaços tanto no meio acadêmico como também nas práticas cotidianas face à urgência das novas demandas sociais dos trabalhadores e a necessidade de se buscar novos aportes teóricos para reflexão de uma problemática muito presente na atualidade no ambiente empresarial.

\section{Pesquisa aplicada junto aos departamentos de Comunicação das organizações}

\section{I. Procedimentos metodológicos}

A pesquisa empírica foi realizada junto a uma amostra de empresas eleitas pelo Guia Exame Maiores e Melhores 2009, que reúne as 1,000 maiores empresas privadas ou estatais do Brasil, com faturamento anual superior a 125,6 milhões de dólares. Quanto à amostra optou-se pela não-probabilística por cotas em função dos setores da economia.

A aplicação da pesquisa empírica junto aos profissionais de Comunicação das 258 empresas selecionadas se deu por meio de um questionário semiestruturado, que foi elaborado a partir de referências teóricas, resgatando elementos como possíveis indicadores das dimensões humana, instrumental e estratégica da Comunicação. Optou-se pela elaboração desse instrumento em aplicativo do Google forms, em função da gratuidade e da praticidade no envio, no recebimento e na tabulação dos dados obtidos.

A primeira parte do questionário solicitava dados gerais da empresa, como nome, endereço completo, segmento (pública ou privada), ramo de atuação, ano de fundação, nome do entrevistado(a), cargo ou função, e há quanto tempo ocupava tal posição. Na segunda parte, as perguntas eram sobre a área de Comunicação na empresa, seu posicionamento e sua importância

Intercom - RBCC 
e estrutura organizacional, com questões de múltipla escolha. A terceira parte se referia às dimensões da Comunicação, dividida em três grupos - dimensão estratégica (nove questões), dimensão instrumental (duas questões) e dimensão humana (seis questões).

\subsection{Retorno e principais resultados}

Procurou-se estabelecer contato visando à aplicação do questionário às 258 empresas, das quais 36 enviaram, efetivamente, as respostas e 26 avisaram que não responderiam ao formulário. Dentre as demais, 176 não deram qualquer retorno à consulta, apesar de muita insistência via correio eletrônico e por telefone. Por fim, 20 das empresas selecionadas se mostraram incomunicáveis, à medida que não foi conseguido nenhum contato.

Se considerarmos como participantes da pesquisa as empresas que se manifestaram e, destas, aquelas que responderam à pesquisa, tivemos um total de $24 \%$ das empresas. O índice de $14 \%$ de questionários respondidos, baseados no número total de empresas, mostra como é difícil o acesso à área de Comunicação das organizações, sobretudo quando se trata da obtenção de informações para uma pesquisa acadêmica. Os motivos alegados foram, por via de regra, a falta de tempo de seus funcionários e a política da empresa de não fornecer informações.

O número total de empresas que responderam ao questionário foi 36 , das quais $78 \%$ são empresas privadas; $11 \%$, públicas; e $11 \%$ não declinaram essa identificação. De fato, nota-se a ausência de uma categoria em que fossem encaixadas as empresas de capital misto - parte de capital público e parte de capital privado.

\section{Análise dos dados obtidos}

\section{I. Dados gerais}

Tabela 1: Segmentos das empresas

\begin{tabular}{lc}
\hline \multicolumn{1}{c}{ Segmento } & $\mathbf{n}$ \\
\hline Empresa Pública & 4 \\
\hline Empresa Privada & 28 \\
\hline Sem resposta & 4 \\
\hline Total & 36 \\
\hline
\end{tabular}


Dividindo as empresas respondentes pelos setores identificados na revista Exame, observamos que 19\% delas são do setor de bens de consumo; $14 \%$, de química/petróleo; $11 \%$, do setor de construção; $8 \%$, de bens de capital; $8 \%$, de mineração; $6 \%$, da indústria automotiva; $6 \%$, da construção; $6 \%$, de serviços; $6 \%$, de transportes. Por fim, dos ramos: atacado, farmacêutico, indústria digital, papel e celulose, têxteis e varejo cada um responde por $3 \%$ dos participantes. Nenhuma empresa do setor de telecomunicações respondeu ao questionário - talvez o motivo principal tenha sido o fato de que o setor na época passava por fusões, mas, mesmo assim, é questionável sua ausência. Por outro lado há um número expressivo de respostas obtidas no setor de bens de consumo, mineração, química e siderurgia, talvez por existir nelas uma preocupação maior com os relacioamentos com seus públicos.

Tabela 2: Setores respondentes da pesquisa

\begin{tabular}{l|c}
\hline \multicolumn{1}{c|}{ Setor } & $\mathbf{n}$ \\
\hline Atacado & 1 \\
\hline Indústria autmotiva & 2 \\
\hline Bens de capital & 3 \\
\hline Bens de consumo & 7 \\
\hline Farmacêutico & 2 \\
\hline Construção & 1 \\
\hline Indústria digital & 3 \\
\hline Mineração & 1 \\
\hline Papel e celulose & 5 \\
\hline Quimica/ Petrolífera & 2 \\
\hline Serviços & 4 \\
\hline Siderurgia & 0 \\
\hline Telecom & 1 \\
\hline Têxteis & 1 \\
\hline Transporte & 36 \\
\hline Varejo & \\
\hline Total & \\
\hline
\end{tabular}

Dos profissionais que responderam à pesquisa, $89 \%$ trabalham com Comunicação; 5,5\%, com recursos humanos, e 5,5\%, em outras áreas. 
Tabela 3: Respondentes por cargo

\begin{tabular}{l|c}
\hline \multicolumn{1}{c|}{ Cargo e função } & n \\
\hline Profissional de Comunicação & 32 \\
\hline Profissional de recursos humanos & 2 \\
\hline Outros & 2 \\
\hline Total & 36 \\
\hline
\end{tabular}

\subsection{Setor/departamento de Comunicação na estrutura organizacional}

A análise das respostas da segunda parte do questionário (setor ou área de Comunicação) indica que, em 61\% das empresas, as atividades referentes à Comunicação são executadas por um departamento; em 14\% delas, ficam a cargo de um profissional; e em $8 \%$ dos casos, cabem a um setor. Não responderam a essa questão $14 \%$ das empresas. Uma das empresas afirmou que a Comunicação é desenvolvida por uma gerência. Nos casos em que as empresas afirmaram que possuem um departamento ou um setor específico, as referidas áreas parecem ser mais estruturadas, contando com diversos profissionais de Comunicação.

Tabela 4: Localização da Comunicação no organograma da empresa

\begin{tabular}{l|c}
\hline \multicolumn{1}{c|}{ Nome da área } & $\mathbf{n}$ \\
\hline Departamento & 22 \\
\hline Setor & 3 \\
\hline Profissional & 5 \\
\hline Outros & 1 \\
\hline Não responderam & 5 \\
\hline Total & 36 \\
\hline
\end{tabular}

A terminologia adotada para designar tais áreas é "Comunicação corporativa" em 31\% das empresas; seguida de "Comunicação", em 14\% delas; e "assuntos institucionais", em 3\% dos casos. Em $33 \%$ das companhias são utilizadas outras terminologias, enquanto que 19\% das empresas não responderam à questão. 
AS DIMENSÕES HUMANA, INSTRUMENTAL E ESTRATÉGICA DA COMUNICAÇÃO...

Tabela 5: Terminologias utilizadas para a área de Comunicação

\begin{tabular}{l|c}
\multicolumn{1}{c|}{ Terminologia } & n \\
\hline Comunicação & 5 \\
\hline Comunicação social & 0 \\
\hline Comunicação corporativa & 11 \\
\hline Assuntos corporativos & 0 \\
\hline Assuntos institucionais & 1 \\
\hline Relações públicas & 0 \\
\hline Outros & 12 \\
\hline Não responderam & 7 \\
\hline Total & 36 \\
\hline
\end{tabular}

\subsection{Dimensões estratégica, instrumental e humana da Comunicação} Organizacional

O fato de a Comunicação ocupar um lugar como staff e junto à presidência pressupõe que é considerada como estratégica. No entanto, isto não se deu na prática com as empresas pesquisadas. Chama-se a atenção (tabela 6, a seguir) de que em $28 \%$ das empresas, as atividades de Comunicação são realizadas junto à diretoria de recursos humanos; em $14 \%$ dos casos, o setor se subordina diretamente à presidência; enquanto que em $5 \%$ das companhias é a diretoria de assuntos corporativos a responsável pela área de Comunicação. Por fim, em 3\% das respondentes a Comunicação é ligada à diretoria comercial e em outros $3 \%$, à de marketing. Outras respostas totalizaram 36\% e 11\% não deram resposta alguma.

Tabela 6: Posição que a Comunicação ocupa na organização

\begin{tabular}{l|c}
\hline \multicolumn{1}{c|}{ Posição } & $\mathbf{n}$ \\
\hline Presidência & 5 \\
\hline Diretoria comercial & 1 \\
\hline Diretoria de assuntos corporativos & 2 \\
\hline Diretoria de marketing & 1 \\
\hline Diretoria de recursos humanos & 10 \\
\hline Outros & 13 \\
\hline Não responderam & 4 \\
\hline Total & 36 \\
\hline
\end{tabular}


Conforme tabela 7, do total das empresas participantes, $41 \%$ afirmaram que a Comunicação Organizacional é considerada pelos seus dirigentes principais como estratégica, contribuindo para os objetivos centrais das atividades empresariais. Em 47\% das companhias, a alta administração considera a Comunicação estratégica em parte, enquanto que $11 \%$ não responderam à pergunta. Não houve resposta negativa.

Tabela 7: Gestores que consideram a Comunicação como uma área estratégica

\begin{tabular}{l|r|r}
\hline \multicolumn{1}{c|}{ Resposta } & n & \multicolumn{1}{c}{ \% } \\
\hline Sim & 15 & 41,67 \\
\hline Não & 0 & 0 \\
\hline Em parte & 17 & 47,62 \\
\hline Não responderam & 4 & 11,11 \\
\hline Total & $\mathbf{3 6}$ & $\mathbf{1 0 0 , 0 0}$ \\
\hline
\end{tabular}

Dentre as respondentes, $25 \%$ afirmaram que o setor de Comunicação sempre é consultado quando se define uma decisão estratégica da empresa; em 39\% das companhias, tal consulta acontece de vez em quando; já em 7\% dos casos, quase nunca se consulta; e $3 \%$ afirmaram que a Comunicação nunca é consultada. Finalmente, $11 \%$ não responderam à questão e $5 \%$ deram outras respostas.

Tabela 8: Frequência com que a área de Comunicação é consultada para tomada de decisão

\begin{tabular}{l|c}
\multicolumn{1}{c|}{ Frequência } & n \\
\hline Sempre & 9 \\
\hline De vez em quando & 14 \\
\hline Quase nunca & 6 \\
\hline Nunca & 1 \\
\hline Outros & 2 \\
\hline Não responderam & 4 \\
\hline Total & 36 \\
\hline
\end{tabular}


Conforme mostra a tabela 9, os respondentes da pesquisa indicaram que a filosofia da empresa tende a privilegiar a Comunicação institucional e a Comunicação interna, diante da Comunicação mercadológica e da Comunicação administrativa.

Tabela 9: Modalidades de Comunicação privilegiadas pela filosofia da empresa

\begin{tabular}{l|r|r}
\multicolumn{1}{c|}{ Quesito } & $\mathbf{n}$ & $\%$ \\
\hline Comunicação institucional & 24 & 68,50 \\
\hline Comunicação administrativa & 13 & 37,00 \\
\hline Comunicação interna & 27 & 77,00 \\
\hline Comunicação mercadológica & 13 & 37,00 \\
\hline $\begin{array}{l}\text { Não. Apenas fazemos propaganda e divulgamos } \\
\text { nossos produtos e serviços e nos valemos da }\end{array}$ & 2 & 5,70 \\
$\begin{array}{l}\text { Comunicação administrativa para o pleno } \\
\text { funcionamento da organização }\end{array}$ & 1 & 2,85 \\
\hline Não sei & 5 & 14,20 \\
\hline Não responderam & 85 & 100,00 \\
\hline Total & & \\
\hline
\end{tabular}

De acordo com a tabela 10, 44,5\% das empresas responderam que têm uma política de Comunicação e a mesma quantidade, que não; $11 \%$ não deram resposta alguma. Esse resultado mostra que não há ainda uma política de Comunicação na maioria das empresas. Parte delas muito provavelmente ainda possui uma mentalidade que não reconhece a diferença que a Comunicação pode fazer em sua reputação institucional e corporativa, bem como nos seus negócios.

Tabela 10: Empresas que possuem política de Comunicação

\begin{tabular}{l|r}
\multicolumn{1}{c|}{ Resposta } & $\mathrm{n}$ \\
\hline Sim & 16 \\
\hline Não & 16 \\
\hline Não responderan & 4 \\
\hline Total & 36 \\
\hline
\end{tabular}


A tabela 11 apresenta o número de profissionais de Comunicação trabalhando nesse setor. Dos respondentes, 89\% deram uma resposta afirmativa e $11 \%$ não responderam à questão. Ninguém respondeu negativamente. Essa resposta aponta que, no âmbito das empresas, o setor vem assistindo a uma crescente especialização, com a contratação de profissionais formados em Comunicação.

Tabela 11: Profissionais especializados em Comunicação

\begin{tabular}{l|c}
\hline \multicolumn{1}{c|}{ Resposta } & $\mathrm{n}$ \\
\hline Sim & 31 \\
\hline Não & 0 \\
\hline Não responderam & 4 \\
\hline Total & 35 \\
\hline
\end{tabular}

A graduação mais frequente entre os profissionais de Comunicação atuantes nos departamentos ou áreas das empresas é a de jornalismo (25 empresas), seguida por relações públicas (23 empresas) e publicidade e propaganda (21 empresas). Os respondentes declararam, ainda, haver profissionais com outras formações atuando na área (16 empresas). A formação em marketing é a menos recorrente (14 empresas).

Tabela 12: Formação dos profissionais na área de Comunicação das empresas respondentes

\begin{tabular}{c|c|c|c|c|c|c|c}
\hline $\begin{array}{c}\text { Quantidade/ } \\
\text { Profissionais }\end{array}$ & 0 & 1 & 2 & 3 & Mais de 3 & $\begin{array}{c}\text { Não } \\
\text { respon- } \\
\text { deram }\end{array}$ & Total \\
\hline Jornalistas & 3 & 8 & 7 & 1 & 9 & 7 & 35 \\
\hline Publicitários & 4 & 10 & 3 & 5 & 3 & 10 & 35 \\
\hline Relações públicas & 2 & 8 & 7 & 1 & 7 & 10 & 35 \\
\hline Marketing & 4 & 2 & 3 & 2 & 3 & 21 & 35 \\
\hline Outros profissoinais & 6 & 7 & 3 & 2 & 4 & 13 & 35 \\
\hline
\end{tabular}

Serviços terceirizados são contratados por $89 \%$ das empresas. Como mostra a tabela 13 , quatro empresas (11\%) não responderam à questão e não foi obtida nenhuma resposta negativa. 
Estima-se que o fato de quase a totalidade das empresas contratarem serviços terceirizados demonstra que há estruturas pequenas de Comunicação e, portanto, toda a parte operacional é feita por terceiros. Observa-se ainda que a prioridade que é dada às agências de Comunicação, o que se justifica por elas possuírem estrutura e experiências adquiridas em função da grande demanda por empresas e agências especializadas nos negócios da Comunicação corporativa.

Tabela 13: Empresas que terceirizam ações de Comunicação

\begin{tabular}{l|c}
\multicolumn{1}{c|}{ Resposta } & $\mathrm{n}$ \\
\hline Terceirizam & 32 \\
\hline Não terceirizam & 0 \\
\hline Não responderam & 4 \\
\hline Total & 36 \\
\hline
\end{tabular}

Observando a tabela 14, conclui-se que os canais mais utilizados para a Comunicação nas empresas são os meios online. De fato, elas vêm adotando com mais frequência as novas mídias e os meios digitais para difundir suas mensagens, tanto internas como externas.

Tabela 14: Canais de Comunicação utilizados

\begin{tabular}{l|c|c}
\hline \multicolumn{1}{c|}{ Quesito } & $\mathrm{n}$ & $\%$ \\
\hline Cartas circulares & 5 & 14,30 \\
\hline Quadro de avisos & 26 & 74,20 \\
\hline Mensagens escritas no holerite & 1 & 2,85 \\
\hline $\begin{array}{l}\text { Mensagens escritas espalhadas } \\
\text { no ambiente organizacional }\end{array}$ & 13 & 37,00 \\
\hline E-mail - correio eletrônico & 27 & 77,00 \\
\hline Intranet & 31 & 88,57 \\
\hline Memorando & 3 & 8,50 \\
\hline Reuniões & 18 & 51,40 \\
\hline Encontros especiais & 18 & 51,40 \\
\hline Outros & 10 & 28,50 \\
\hline Não responderam & 5 & 14,30 \\
\hline
\end{tabular}


Dentre as respondentes, $78 \%$ apontaram como verdadeira a afirmativa "a Comunicação é utilizada para transmissão de metas e objetivos organizacionais", enquanto que $8 \%$ a consideraram falsa. Já a segunda afirmativa ("a Comunicação que vem sendo produzida pode ser considerada eficiente") foi apontada como verdadeira por $83 \%$ das empresas e falsa por 3\%. A terceira sentença ("a Comunicação que vem sendo produzida pode ser considerada eficaz") foi reputada verdadeira por $53 \%$ das respostas e falsa por $33 \%$ delas. Por fim, a frase "Há um volume excessivo de informações divulgadas por diferentes meios" foi julgada verdadeira por 39\% das empresas pesquisadas e falsa por $47 \%$ delas. As empresas que não responderam a essa questão totalizaram 14\%.

Sobre as redes de relacionamento informal, $44 \%$ disseram valorizá-las, 39\% afirmaram que a valorizam em parte e $6 \%$ não a valorizam. Não responderam à questão $11 \%$ das empresas.

Tabela 15: Valorização das redes de relacionamento informal

\begin{tabular}{l|c}
\hline \multicolumn{1}{c|}{ Respostas } & $\mathrm{n}$ \\
\hline Sim & 16 \\
\hline Não & 2 \\
\hline Em parte & 14 \\
\hline Não responderam & 4 \\
\hline Total & 36 \\
\hline
\end{tabular}

Acerca da existência de espaços físicos, dentro da empresa, que contribuem para o relacionamento interpessoal entre funcionários, $72 \%$ das respondentes afirmaram possuir tais espaços, enquanto $14 \%$ não os possuem. Dentre os respondentes, $14 \%$ deixaram de responder à questão. $O$ fato de a grande maioria das empresas destinar um espaço físico para interação entre seus funcionários indica novamente a penetração, nas corporações, de práticas voltadas á valorização das pessoas e a um convívio mais fraterno e descontraído dos empregados. Em princípio, isto sinaliza algum indicador de qualidade de vida no trabalho. 
AS DIMENSÕES HUMANA, INSTRUMENTAL E ESTRATÉGICA DA COMUNICAÇÃO...

Tabela 16: Empresas que possuem espaços físicos de interação

\begin{tabular}{l|c}
\hline \multicolumn{1}{c|}{ Respostas } & $\mathrm{n}$ \\
\hline Possuem & 26 \\
\hline Não possuem & 5 \\
\hline Não responderam & 5 \\
\hline Total & 36 \\
\hline
\end{tabular}

Para 41\% das respondentes, a rede informal de relações entre os empregados contribui para um bom clima organizacional. Para $3 \%$, não contribui e 39\% afirmam que em parte contribui. Dentre elas, $17 \%$ das empresas deixaram de responder a pergunta, como mostra a tabela 17. Vale observar que o diálogo informal entre os funcionários, antes ignorado por todas as empresas, hoje pode ser visto como fato positivo ou negativo, dependendo das circunstâncias e dos contextos.

Tabela 17: Contribuição das redes informais

\begin{tabular}{l|c}
\hline \multicolumn{1}{c|}{ Respostas } & $\mathrm{n}$ \\
\hline Contribuem & 15 \\
\hline Não contribuem & 1 \\
\hline Contribuem em parte & 14 \\
\hline Não responderam & 6 \\
\hline Total & 36 \\
\hline
\end{tabular}

Ainda com foco na dimensão humana, questionou-se sobre a Comunicação participativa e sobre o fluxo de Comunicação horizontal das empresas estudadas. Entre as respondentes, 28,5\% afirmaram que o funcionário pode enviar suas sugestões por meio de vários fluxos comunicacionais; 5,7\% responderam que há grupos intermediários entre os empregados e a alta administração; 11,4\% promovem encontros e reuniões especiais, destinadas a ouvir o que o funcionário tem a dizer; $17,1 \%$ consideram que, a partir do momento em que as normas são transmitidas, cabe ao funcionário segui-las. Finalmente, 22,8\% das empresas afirmam manter diálogo constante entre gestores e funcionários. Das empresas pesquisadas, $14,2 \%$ não responderam e $2,85 \%$ deram outras respostas. 
Tabela 18: Comunicação participativa nas organizações

\begin{tabular}{l|c|c|}
\hline \multicolumn{1}{c|}{ Quesito } & $\mathrm{n}$ & $\%$ \\
\hline $\begin{array}{l}\text { O empregado pode se manifestar e enviar suas } \\
\text { sugestões por meio de vários canais de Comunicação }\end{array}$ & 10 & 28,50 \\
\hline $\begin{array}{l}\text { Existem comitês formados para intermediar as relações } \\
\text { e interesses entre os empregados e a alta administração }\end{array}$ & 2 & 5,70 \\
\hline $\begin{array}{l}\text { Frequentemente são feitas reuniões e/ou encontros } \\
\text { especiais abertos a ouvir o que o empregado tem a } \\
\text { dizer }\end{array}$ & 4 & 11,40 \\
\hline $\begin{array}{l}\text { As orientações e as normas são transmitidas e cabe aos } \\
\text { empregados segui-las }\end{array}$ & 6 & 17,10 \\
\hline $\begin{array}{l}\text { Há trocas de informações com frequência entre } \\
\text { gestores e gerentes ... }\end{array}$ & 8 & 22,80 \\
\hline Outros & 5 & 2,85 \\
\hline Vazio & 36 & 100,00 \\
\hline Total & & 14,20 \\
\hline
\end{tabular}

A gestão de Comunicação promove ações diretamente relacionadas à qualidade de vida no trabalho em $64 \%$ das empresas pesquisadas. Tal não acontece em $22 \%$ delas e $14 \%$ não responderam à questão. Pode-se concluir, pois, que a maior parte das empresas se preocupa com a qualidade de vida de seus trabalhadores, considerando que o bem estar de cada um influencia positivamente seu rendimento no trabalho, a demonstrar que, em princípio, a visão humanística veio tomar o lugar da perspectiva do "trabalhador máquina", existente na primeira revolução industrial. Segundo esse entendimento, o funcionário não é apenas uma peça da engrenagem empresarial, mas um capital humano que precisa ser considerado sob novos olhares.

Tabela 19: Ações de qualidade de vida no trabalho

\begin{tabular}{l|c}
\multicolumn{1}{c|}{ Respostas } & $\mathrm{n}$ \\
\hline Possui & 23 \\
\hline Não possui & 5 \\
\hline Não respondeu & 5 \\
\hline Outros & 3 \\
\hline Total & 36 \\
\hline
\end{tabular}


Dentro dessa visão humana de tratamento do funcionário, que revela a dimensão humana da Comunicação, perguntou-se quais os instrumentos mais usados pelas empresas para promover o diálogo entre gestores e funcionários. A essa questão, $43 \%$ das respondentes apontaram os programas "face-a-face" com presidente; $65,7 \%$ realizam reuniões entre superiores e subordinados; $60 \%$ utilizam um espaço na intranet; $25,7 \%$ faz uso da caixa de sugestões; $20 \%$ afirmam que há um "e-mail" direto ao presidente; $45,7 \%$ indicam as conversas informais e $43 \%$ promovem eventos periódicos para manter um diálogo com os funcionários. Não responderam à questão $14,2 \%$ das empresas e $22,8 \%$ deram outras respostas.

A alta porcentagem no uso de intranet para diálogo com funcionários corrobora a percepção de grande inserção da sociedade nos meios digitais, da Internet e seus recursos de redes sociais e relacionamentos, refletida também nas empresas. Um grande número de empresas faz uso de um espaço na Internet apenas para funcionários. Já a caixa de sugestões, por ser um método mais formal e impessoal, é pouco usada entre as empresas estudadas, sendo adotada por apenas 25,7\% delas. Os programas especiais "face-a-face" com o presidente e o e-mail ao presidente são exemplos de uma estratégia voltada a que o funcionário se sinta parte da empresa e participante de suas atividades, tendo, inclusive, a chance de conversar com a alta administração para transmitir suas idéias.

Entre as outras respostas dadas à questão, obtiveram-se como métodos o "Canal Aberto" destinado a denúncias; a "bolsa de ideias" que capta sugestões dos trabalhadores; a ouvidoria; o jornal interno; os treinamentos; as reuniões entre áreas de negócios; a reunião mensal e os veículos impressos. 
Tabela 20: Meios para promover o diálogo entre gestores e funcionários

\begin{tabular}{l|r|r}
\hline \multicolumn{1}{c|}{ Meios } & \multicolumn{1}{c|}{$\mathrm{n}$} & \multicolumn{1}{c}{$\%$} \\
\hline Programa especial "face-a-face" - "Fala do presidente" & 15 & 43,00 \\
\hline Reuniões entre superior - subordinado & 23 & 65,70 \\
\hline Espaço na Intranet & 21 & 60,00 \\
\hline Caixa de sugestões & 9 & 25,70 \\
\hline E-mail direto ao presidente & 16 & 20,00 \\
\hline Diálogos informais & 15 & 45,70 \\
\hline $\begin{array}{l}\text { Eventos específicos e periódicos para discussão de temas } \\
\text { de interesse de todos }\end{array}$ & 8 & 43,00 \\
\hline Outros & 5 & 14,80 \\
\hline Vazio & 116 & 100,00 \\
\hline Total & &
\end{tabular}

\section{Conclusões gerais}

A pesquisa realizada nos permite tirar algumas conclusões que são destacadas a seguir.

Primeiro a dificuldade encontrada pelos pesquisadores para estabelecer os contatos e para conseguir realizar estudos dessa natureza. Essas constatações expressam que não há uma coerência entre o discurso das empresas quando se dizem abertas aos públicos e à opinião publica em relação aos seus comportamentos institucionais. Outra constatação, já observada em pesquisas acadêmicas anteriores por esta autora e de seus orientandos em nível de mestrado e doutorado, é a falta de uma cultura de valorização da pesquisa empírica na área de Comunicação por parte das empresas.

Em relação aos segmentos da economia que compôs a amostra, chama atenção do fato das telecomunicações não terem respondido, mesmo que algumas delas se encontravam em momentos de fusão com outras empresas do mesmo setor. $\mathrm{O}$ grande número de respostas obtidas no setor de bens de consumo, mineração, química e siderurgia pode ser explicado pela grande atenção que cada um desses setores precisa dedicar ao consumidor, aos públicos envolvidos e à sociedade, pois suas atividades são diretamente ligadas a riscos socioambientais. 
Quanto ao setor ou departamento de Comunicação existente nas empresas pesquisadas, nota-se uma frequência acentuada e bastante positiva, na medida em que as atividades são executadas predominantemente pelos departamentos específicos e por profissionais formados em Comunicação. Outro fato positivo foi que dos profissionais responderam a pesquisa $89 \%$ trabalham com Comunicação. Pode-se deduzir que para muitas das empresas que responderam a Comunicação essa se mostra relevante para seus gestores. Outra constatação positiva foi ver que os profissionais de Relações Públicas estão muito presentes nesses setores/departamentos, perfazendo um total de 23 em relação aos jornalistas que somam 25. Desmestifica-se assim aquela percepção do senso comum de que a área de Relações Públicas perde espaço para outras profissões.

A variedade de terminologias utilizadas para nomear os departamentos indica que ainda falta no mercado uma maior clareza do real significado das funções profissionais e atividades gerais e específicas da área de Comunicação, quando aplicada ao mundo corporativo. Chama a atenção ainda que, em um bom número de empresas (10), o setor de Comunicação esteja vinculado à diretoria de recursos humanos e apenas cinco à presidência. Essa variedade de denominações e vinculações pode ser atribuída ao fato de que a Comunicação e as relações públicas são áreas ainda recentes nas empresas em geral.

Ao se confrontar os dados obtidos da terceira parte da pesquisa relativos às possíveis configurações da existência das dimensões estratégica, instrumental e humana da Comunicação Organizacional pode-se concluir que não é tão simples aferir, por meio de um questionário, se de fato essas dimensões estão contempladas. As questões levantadas tiveram com referência possíveis indicadores conceituais que de alguma forma poderiam expressar tais dimensões. Entretanto é bom esclarecer que essas não ocorrem de forma isolada, mas de forma simultânea e complementar.

Em relação à dimensão estratégica pelas respostas obtidas observa-se que, para grande maioria das empresas consultadas, ela só existe em parte. Pois, falta uma política de Comunicação mais definida e integrada, poucos departamentos respondem 
diretamente à alta gestão, a área não é consultada para decisões estratégicas de forma constante, entre outros aspectos que possam caracterizar a Comunicação na estrutura organizacional como fator estratégico de resultados. Em todo esse contexto chama atenção o fato da maioria das empresas consultadas privilegiarem muito mais a Comunicação interna e institucional do que a mercadológica.

A transmissão de informações com a utilização de todos os meios possíveis para o alcance de objetivos e metas organizacionais de forma eficiente e eficaz foi bastante acentuada pela maioria das empresas que responderam a pesquisa, o que atesta como a dimensão instrumental está presente na vida das organizações.

Em relação à dimensão humana, embora reconhecendo as limitações de se aplicar um questionário para identificar possíveis características de sua presença, considera-se que pelos dados obtidos as percepções são positivas na maioria das empresas estudadas. Há valorização da rede informal, espaços físicos de convivência para os trabalhadores, programas voltados para qualidade de vida no trabalho e existem vários meios de Comunicação que são utilizados para promover uma Comunicação participativa, por meio do diálogo entre a cúpula dirigente e os funcionários, entre outros pontos indicativos. Essa questão aponta para uma quebra de paradigma. Se antes se pensava que a Comunicação da empresa possuía apenas fluxos verticais, fortemente hierarquizados, hoje cresce a percepção de que as empresas adotam fluxos diferenciados, como o horizontal, transversal e circular. Evidentemente, para uma certificação mais segura de que a questão humana constitui de fato uma filosofia por parte da direção exigiria, sobretudo, a realização de uma pesquisa-ação e participante do pesquisador.

O presente estudo realizado nos possibilitou a ver a Comunicação nas organizações com novos olhares e capazes de dimensionar a questão humana como algo que precisa ser melhor resgatado e valorizado. Propõe-se a pensar essa Comunicação e suas principais dimensões numa perspectiva crítica e interpretativa, superando a visão meramente mecanicista e instrumental tão presente no dia-a- dia do ambiente organizacional.Apesar de uma evolução gradativa dos modelos mecânicos da transmissão unilateral de informações para a implantação de processos comunicativos mais interativos 
graça sobretudo às mídias sociais, ainda falta em grande parte das empresas em geral uma Comunicação que permita a abertura de canais dialógicos de fato e que as pessoas sejam consideradas em primeiro lugar.

\section{Referências}

FURTADO, Odair. Psicologia e relação de trabalho: em busca de uma leitura crítica e uma atuação compromissada. In: BOCK, Ana M. Bahia (Org.). A perspectiva sócio-histórica na formação em psicologia. Petrópolis: Vozes, 2003. P.211-239.

KUNSCH, Margarida M. Krohling. A dimensão humana nas organizações. In: KUNSCH, Margarida M. Krohling (Org.). A comunicação como fator de humanização das organizações. São Caetano do Sul: Difusão, 2010.

. Comunicação Organizacional: surgimento e evolução das práticas, conceitos e dimensões.In:KUNSCH, Margarida M. Krohling (Org.). Comunicação organizacional: histórico, fundamentos e processos. v. 1. São Paulo: Saraiva, 2009.

. Comunicação Organizacional: conceitos e dimensões dos estudos e das práticas. In: MARCHIORI, Marlene (Org.). Faces da cultura e da comunicação organizacional. São Caetano do Sul: Difusão, 2006. p167-190.

KUNSCH, Margarida M. Krohling (Org.). A Comunicação como fator de humanização das organizações. São Caetano do Sul: Difusão, 2010.

LANCMAN, Selma."Uma relação indissociável". MSG-Revista de Comunicação e Cultura. São Paulo: Abreje e Lazuli Editora, ano 1, n. 4, p. 68-69, 2009.

WOlTON, Dominique. Pensar a Comunicação. Trad. de Zélia Leal Adghirni. Brasília: Editora UnB, 2004. 


\section{Luiz Beltrão}

\section{Pioneiro das Ciências da Comunicação no Brasil}

A publicação do livro "Luiz Beltrão, pioneiro das ciências da Comunicação no Brasil”, coincide com a celebração do $90^{\circ}$ aniversário de nascimento do intelectual nordestino que promoveu uma revolução metodológica no ensino de Jornalismo e criou as bases teóricas para o desenvolvimento de um pensamento comunicacional autenticamente brasileiro.

A coletânea reúne ensaios que dão conta da personalidade polifacética de Luiz Beltrão: jornalista, ficcionista, pedagogo, cientista, memorialista, sempre denotando espírito inovador.

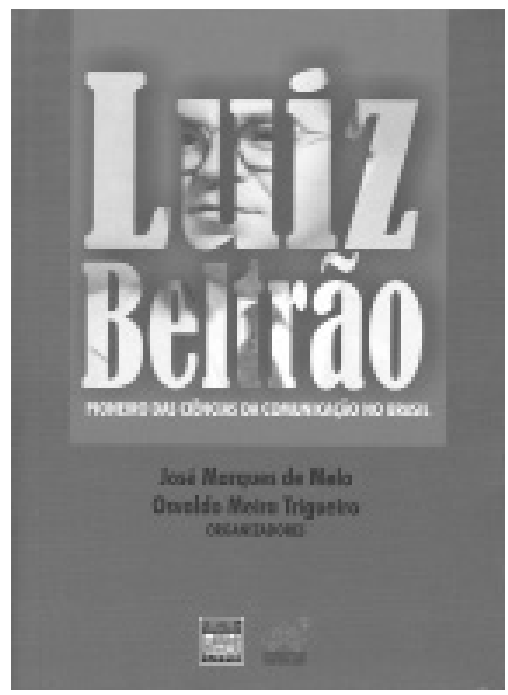

FAÇA SEU PEDIDO

pelo telefone (0xx11) 2574-8477,

e-mail: intercom@usp.br

ou acesse a Livraria Virtual da Intercom:

http://www.intercom.org.br 